\title{
Epidemiological and Cost Analysis of Self-Poisoning Cases in Ankara,Turkey
}

\author{
Gulsum Kavalci ${ }^{1,}$; Filiz Banu Ethemoglu ${ }^{1}$; Asli Batuman ${ }^{1}$; Dilber Kumral ${ }^{1}$; Cengizhan Emre ${ }^{1}$; \\ Meltem Surgit ${ }^{1}$; Alev Akdikan ${ }^{1}$; Cemil Kavalci ${ }^{2}$ \\ ${ }^{1}$ Department of Anesthesiology and Reanimation, Yenimahalle State Hospital, Ankara, Turkey \\ ${ }^{2}$ Department of Medicine Emergency, University of Baskent, Ankara, Turkey \\ ${ }^{*}$ Corresponding Author: Gulsum Kavalci, Department of Anesthesiology and Reanimation, Yenimahalle State Hospital, Ankara, Turkey. Tel: +90-3125085026, Fax: +90-3123125346, \\ E-mail:gkavalci@yahoo.com
}

Received: February 18, 2013; Revised: November 22, 2013; Accepted: October 1, 2014

Background: Poisoning is a global public health problem. Self-poisoning has potentially serious consequences. Follow-up studies have found that $3-10 \%$ of self-harm patients eventually succeed.

Objectives: This study was designed to investigate the epidemiological, clinical and economical aspects of deliberate self-poisoning patients admitted to Yenimahalle State Hospital Intensive Care Unit.

Patients and Methods: The study was carried out retrospectively in Ankara Yenimahalle State Hospital. It included Seventy-one patients over 16 years of age who were admitted to the hospital due to poisoning during 2012. Exposed poisons were classified into one of three categories; pharmaceuticals, pesticides, and alcohols. Cost account was based on the medical invoices at patient discharge. Data were compared using Student's T test and chi-square test. A P value of less than 0.05 was considered significant.

Results: The female/male ratio was 2.55. The mean age of the 71 poisoned patients was $28.92 \pm 11.51$ years. Most of the poisoning agents were pharmaceuticals (68 cases). Among the pharmaceuticals, antidepressants were involved most often, followed by analgesics. There was no statistically significant difference between pharmaceutical agents in terms of hospital cost $(P>0.05)$. The mean length of hospital stay was $6.4 \pm 4.3$ days. There was a statistically significant difference between the lengths of stay of patients in terms of hospital cost $(\mathrm{P}<0.05)$. Conclusions: The patient cost increased as the length of stay increased due to the policy of bundle pricing.

Keywords:Poisoning; Cost; Intensive Care Unit

\section{Background}

Poisoning is a global public health problem. Deliberate self-harm (DSH) is a major health problem in developing countries $(1,2)$. Deliberate self-harm is common among young people, especially in certain subpopulations. It may be associated with depression, suicide attempt and some other psychiatric disorders (2). Deliberate self-poisoning is one of the commonest reasons for general hospital admissions in the UK, and it represents a considerable economic burden (3-5). Self-poisoning has potentially serious consequences; follow-up studies have found that $3-10 \%$ of self-harm patients eventually succeed $(4,5)$.

\section{Objectives}

This study aimed to investigate the epidemiological, clinical and economic aspects of deliberate self-poisoning patients admitted to Yenimahalle State Hospital Intensive Care Unit (ICU).

\section{Patients and Methods}

This study was cross-sectional and retrospectively car- ried out at Ankara Yenimahalle State Hospital, Turkey. There were no ethical issues associated with this study. The authors worked according to the Helsinki declaration. We included 71 patients, who were admitted to the hospital's ICU due to self-poisoning during 2012. Deliberate self-poisoning is defined as the deliberate ingestion of substances intended to cause harm. Characteristics such as age and gender of the patients, poisoning agents, outcomes (discharged, referred, admitted, death etc.), and cost were recorded. Inclusion/exclusion criteria are shown in Table1. Exposed poisons were classified into one of the three categories: pharmaceuticals, pesticides, and alcohols. Pharmaceuticals were subcategorized into antidepressants, analgesics, other psychotropic agents (including antipsychotics, benzodiazepines, lithium, etc.), antiepileptics, antibiotics, antihypertensives, others (including vitamins, antihistamines, antiemetics, antidyspeptic drugs, anti-ulcer drugs, hormones, antidiabetics, skeletal muscle relaxants, warfarin, drugs for the common cold, etc.), and unidentifiable. The number of ingested pharmaceuticals was also recorded. Cost account was based on the medical invoices at patient discharge.

Copyright (C) 2014, Iranian Red Crescent Medical Journal. This is an open-access article distributed under the terms of the Creative Commons Attribution-NonCommercial 4.0 International License (http://creativecommons.org/licenses/by-nc/4.0/) which permits copy and redistribute the material just in noncommercial usages, provided the original work is properly cited. 
For statistical analysis, patients' data were assessed by the SPSS version 18.0 software. Quantitative variables were expressed as mean \pm standard deviation. Frequency and percentage distribution were used for the evaluation of data. The chi-squared test was used for comparison of the categorized variables. Distribution of the invoices was evaluated with the Kolmogorov-Smirnov test and normally distributed invoices were compared using Student's T test and ANOVA test. For the determination of factors effective on patient cost, logistic regression analysis was done. A P value of less than 0.05 was accepted as significant.

\section{Results}

Of the 1291 patients admitted to the critical care unit during this one-year period, 71(5\%) had poisoning. Among these cases, $71.8 \%$ were female. The female/male ratio was 2.55. There was no statistically significant difference between the two genders in terms of hospital cost $(\mathrm{P}>0.05)$ (Table 2). The mean age of the 71 poisoned patients was $28.92 \pm 11.51$ years. Most of our patients (42.3\%) were under 26 years of age (Table 2 ). There was no statistically significant difference regarding the hospital cost of different age groups $(\mathrm{P}>0.05)$ (Table 2$)$. Mean systolic blood pressure was $116.96 \pm 14.2 \mathrm{mmHg}$, mean diastolic blood pressure was $76.49 \pm 7.85 \mathrm{mmHg}$, and mean heart rate was $90.27 \pm 2.56 \mathrm{bpm}$. Gastric lavage was performed in $49.3 \%$ of patients. Treatment modalities are summarized in Table 2. There was no statistically significant difference between treatment modalities in terms of hospital cost $(P>0.05)$ (Table 3). Furthermore, $67.6 \%$ of patients were intoxicated by a single agent, and $14.1 \%$ were intoxicated by two agents (Table 4 ). There was a statistically significant difference between hospital costs according to the number of type of agents $(\mathrm{P}<0.05)$ (Table 4$)$.

Most of the poisoning agents were pharmaceuticals (68 cases). The distribution of poisoning agents is shown on the Table 3. There was no statistically significant difference between the poisoning agents in terms of hospital cost $(\mathrm{P}>0.05)$ (Table 3$)$. Among the pharmaceuticals, antidepressants were most often involved, followed by analgesics (Table 4 ). There was no statistically significant difference between pharmaceutical agents in terms of hospital cost $(\mathrm{P}>0.05)$ (Table 4). All patients were evaluated, treated, and discharged from the critical care unit (100\%). The mean length of hospital stay was $6.4 \pm 4.3$ days. There was a statistically significant difference between the lengths of stay in terms of hospital cost $(\mathrm{P}<$ 0.05) (Table 5). No patient died due to poisoning. For the determination of factors effective on patient cost, logistic regression analysis was done. Length of stay, analgesics and antihypertensive poisonings were determined as factors influencing patient costs (Table 6).

Table 1. Inclusion/Exclusion Criteria

\begin{tabular}{lc}
\hline Inclusion Criteria & Exclusion Criteria \\
\hline Patients over 16 years of age & patients under 16 years of age \\
$\begin{array}{l}\text { Patients who were admitted to the hospital's ICU with deliber- } \\
\text { ate self-poisoning }\end{array}$ \\
\hline
\end{tabular}

Table 2. Demographic Features of Patients ${ }^{a}$

\begin{tabular}{|c|c|c|c|}
\hline Demographic Features & Results & Cost, \$ & P Value \\
\hline Gender & & & $P>0.05$ \\
\hline Male & $20(32.3)$ & $401.57 \pm 326.32$ & \\
\hline Female & $51(71.8)$ & $329.57 \pm 218.47$ & \\
\hline Age groups & & & $\mathrm{P}>0.05$ \\
\hline $16-25$ & $30(42.3)$ & $356.40 \pm 248.54$ & \\
\hline $26-35$ & $27(38)$ & $268.05 \pm 163.99$ & \\
\hline $36-45$ & $7(9.9)$ & $509.12 \pm 303.97$ & \\
\hline $46-55$ & $5(7)$ & $473.43 \pm 490.97$ & \\
\hline $56-65$ & $1(1.4)$ & 498.20 & \\
\hline$>66$ & $1(1.4)$ & 480.66 & \\
\hline
\end{tabular}

${ }^{\mathrm{a}}$ Data are Presented as No. (\%) or Mean \pm SD. 
Kavalci G et al.

Table 3. Poisoning Agents and Treatment Modalities ${ }^{\mathrm{a}}$

\begin{tabular}{lccc}
\hline & Results, $\mathbf{N}(\%)$ & Cost, $\mathbf{S}$ & P Value \\
\hline Treatment Modality & & & P $>0.05$ \\
\hline Gastric lavage & $35(49.3)$ & $357.30 \pm 272.13$ & \\
\hline Active charcoal & $38(53.5)$ & $353.19 \pm 264.33$ & $\mathrm{P}>0.05$ \\
\hline Antidote & $9(12.7)$ & $413.89 \pm 125.18$ & \\
Substance & & & $351.265 \pm 256.48$ \\
\hline Pharmaceutical & $68(95.8)$ & $232.88 \pm 173.49$ & 487.82 \\
\hline Alcohol & $2(2.8)$ & & \\
\hline Pesticide & $1(1.4)$ & & \\
\hline
\end{tabular}

${ }^{\mathrm{a}}$ Data are Presented as No. (\%) or Mean \pm SD.

Table 4. Pharmaceutical Agents (one or multiple) Involved in Poisoning a

\begin{tabular}{|c|c|c|c|}
\hline & Results & Cost, \$ & P Value \\
\hline Numbers of Agent & & & $\mathrm{P}<0.05$ \\
\hline 1 & $48(67.6)$ & $320.11 \pm 198.6$ & \\
\hline 2 & $10(14.1)$ & $557.52 \pm 468.50$ & \\
\hline 3 & $6(8.5)$ & $295.65 \pm 124.35$ & \\
\hline 4 & $7(9.9)$ & $303.51 \pm 93.13$ & \\
\hline Pharmaceuticals & & & $\mathrm{P}>0.05$ \\
\hline Antidepressant & $31(43.7)$ & $318.59 \pm 247.64$ & \\
\hline Analgesic & $28(39.4)$ & $365.08 \pm 221.05$ & \\
\hline Other psychotropic & $3(4.2)$ & $827.06 \pm 668.83$ & \\
\hline Antiepileptic & $2(2.8)$ & $266.90 \pm 24.69$ & \\
\hline Antibiotic & $6(8.5)$ & $306.48 \pm 201.73$ & \\
\hline Antihypertensives & $4(5.6)$ & $558.28 \pm 520.65$ & \\
\hline Others & $16(22.5)$ & $435.62 \pm 298.17$ & \\
\hline Unidentifiable & $9(12.7)$ & $270.71 \pm 185.41$ & \\
\hline
\end{tabular}

${ }^{\mathrm{a}}$ Data are Presented as No. (\%) or Mean $\pm \mathrm{SD}$.

Table 5. Cost and Length of Stay ${ }^{\mathrm{a}}$

\begin{tabular}{lccc}
\hline Length of Stay & Results & Cost, $\mathbf{S}$ & P Value \\
\hline $\mathbf{1}$ & $8(11.3)$ & $61.41 \pm 52.36$ & $<0.05$ \\
$\mathbf{2}$ & $31(43.7)$ & $236.72 \pm 85.86$ & \\
$\mathbf{3}$ & $24(33.8)$ & $423.65 \pm 128.87$ & \\
$\mathbf{4}$ & $5(7)$ & $648.70 \pm 103.02$ & \\
$\mathbf{5}$ & $2(2.8)$ & $1150.98 \pm 4.88$ & \\
$\mathbf{7}$ & $1(1.4)$ & 1300 & \\
\hline
\end{tabular}

${ }^{\mathrm{a}}$ Data are Presented as No. (\%) or Mean \pm SD. 
Kavalci G et al.

\begin{tabular}{|c|c|c|}
\hline Variable & $\mathbf{R R}(95 \% \mathrm{CI})$ & P Value \\
\hline Length of stay ${ }^{a}$ & $0.96(209.1-262.3)$ & 0.000 \\
\hline Analgesic & $0.189(11.4-183.3)$ & 0.027 \\
\hline Antihypertensives & $-0.215(-365.6-103.1)$ & 0.001 \\
\hline Sex & $-0.061(-95.5-26.8)$ & 0.265 \\
\hline Age groups & $0.090(-4.5-46.9)$ & 0.104 \\
\hline Numbers of agent & $0.012(-40.3-46.5)$ & 0.886 \\
\hline Antidepressant & $-0.102(-122.8-19.6)$ & 0.152 \\
\hline Antipsychotropic & $0.020(-149.7-211.1)$ & 0.734 \\
\hline Antiepileptic & $0.020(-139.0-199.4)$ & 0.722 \\
\hline Antibiotic & $-0.047(-180.6-95.9)$ & 0.541 \\
\hline Alcohol & $0.002(-170.1-175.8)$ & 0.974 \\
\hline Pesticide & $-0.005(-231.0-211.4)$ & 0.930 \\
\hline Gastric lavage & $0.080(-41.6-121.9)$ & 0.329 \\
\hline Active charcoal & $-0.144(-157.6-12.1)$ & 0.091 \\
\hline Antidote & $-0.092(-202.2-63.3)$ & 0.299 \\
\hline
\end{tabular}

${ }^{\mathrm{a}}$ Logistic regression analysis.

\section{Discussion}

Poisonings are important causes of mortality and morbidity. Suicide is the second most common cause of death among adolescents and young adults (6). In a study of adult poisoning cases carried out in Canada, acute intoxications accounted for $0.7 \%$ of admissions (7). Hanssens et al. showed that acute poisoning cases were $0.18 \%$ of all hospital admissions (8). Another study on poisonings carried out in England revealed that 1.2\% of hospital visits were due to acute poisonings (6). Kapur et al. reported that self-poisoning accounted for $0.31 \%$ of hospital admissions (3). Mashreky et al. reported that poisoning cases were $0.073 \%$ of hospital admissions (9). Cengiz et al. reported that acute poisoning cases were $0.18 \%$ of all hospital admissions (10). According to our results, our patient population had an acute poisoning ratio of $0.05 \%$ which is less than that reported from other parts of Turkey (0.004-2.4\%) (11-16). Our results were consistent with the literature. In previous reports, the female/male ratio varied between 1.7 and 3 (12-20). The female/male ratio in our patients was 2.55. Interestingly, this ratio has been reported to be lower (approximately $1 / 1$ ) in various developed countries $(7,21-23)$. As in other reports, the majority of our patients were young, where $42.3 \%$ were under 26 years old; similar to proportions in two international studies and in two studies from Turkey $(7,8,17$, 18). Our results were consistent with the literature. We suggest that economical and social issues, such as unemployment and marriage, more commonly affect this age group. The substances involved in most of the poisonings in our study were pharmaceutical agents (95.8\%), which is in agreement with reports from other regions in Tur- key (12-16). In studies from other countries, pharmaceuticals were also found to be the most common agents involved in acute poisoning (21-24). Cengiz et al. reported that pharmaceutical agents were the cause of $51.2 \%$ of intoxications in patients admitted to the intensive care unit (10). Differences between developmental and sociocultural levels of the regions in which the study was conducted may have affected and changed the study results. Regarding the type of pharmaceutical agents involved in poisonings of Turkey, analgesics were reported to be the most frequently ingested agents in some studies $(27.6 \%$ in our study) (12-15), whereas antidepressants were most commonly used in the study reported by Baydin et al.(18). Antidepressants were most commonly used in our study (43.7\%). Antidepressants are easily available without a prescription in Turkey. Alcohols were the second most common toxic substance in our study (2.8\%) (Table 2 ).

The ratio of alcohol to all other poisoning agents was 3.1$18 \%$ in previous studies $(1,22-25)$. White et al. reported that alcohol poisoning increased in young adults between 1999-2008 (26). Our results were in accordance with the literature. In Islamic communities alcohol consumption is less than western communities, thus poisoning rates might be lower in Turkey. Pesticides were the third most common toxic agent (1.4\%). Cengiz et al. reported that pesticide poisoning rate was 10\% (10). Khurram and Mahmood reported that pesticide poisoning rate was $21.3 \%$ (27). Studies from non-agricultural areas in Turkey reported a much lower percentage of poisonings involving pesticides, ranging between $0.9 \%$ and $1.6 \%(15,28)$, while studies from agricultural areas reported a rate of pesticide involvement of $12-26 \%(18,29)$. In such regions, pesticides are often sold in local markets and kept at home $(27,28)$. We think that the rate of pesticide poisoning in our study was low due to a low ratio of agricultural areas in the studied region. Mortality rate of $0-5.8 \%$ has been reported in the literature $(8-17,19)$. Our mortality rate $(0 \%)$ was consistent with the literature. Early intervention decreased the mortality rate. The ratio of poisoning by a single agent was reported as $55-74 \%$ in previous studies $(16,17,24)$, while $67.6 \%$ of our patients were intoxicated by a single agent. Our results are similar to the literature. Suicidal attempts are commonly impulsive and patients ingest a single agent that is easily reachable rather than multiple agents. The duration of the intensive care stay ranged between 1.6 and 6.4 days $(2,5,10,30)$ in the literature. The duration of the intensive care stay in our study was $6.4 \pm 4.3$ days. Increased defensive medicine approaches and malpractice law may have increased the length of stay. Costs of poisoning cases treated at the intensive care unit have been scarcely studied. Serinken et al. reported a hospital cost of $\$ 144.06$ for patients admitted for suicide (2). Kapur et al. reported that the cost of intensive care unit ranged between $£ 217$ and $£ 432$ (3). Shadid et al. reported that the average hospital cost of a poisoning patient was \$255 (31). D’Mello et al. reported that the cost of hospital treatment for patients who over- 
dosed on tricyclic antidepressants was four times greater than the cost of treatment for patients who overdosed on selective serotonin reuptake inhibitors (29). Yeo et al. reported that mean cost of a poisoning patient was $£ 425.64$ (5). The average cost in our study was $\$ 349$. We think that the difference between the costs is a result of varying policies of charging of services. Serinken et al. from Turkey reported a cost of $\$ 144.06$ (2) while we determined a cost of $\$ 349$. We observed a difference in hospital cost that was associated with the number of ingested agents and length of hospital stay. We feel that our average cost has been increased by the bundle pricing that was put into effect in our country during an intervening period of six years. Poisoning is common in adults in our studied region; the risk being highest in females and younger adults. The patient cost increases as the length of hospital stay increases due to the policy of bundle pricing.

\subsection{Limitation of the Study}

The major limitation of this study was its retrospective nature and small number of patients included in the study due to late establishment of ICU in 2012.

\section{Authors' Contributions}

Gulsum Kavalci: study concept and design. Filiz Banu Ethemoglu and Asli Batuman: acquisition of data. Gulsum Kavalci, Dilber Kumral and Cengizhan Emre: drafting of the manuscript. Meltem Surgit: administrative, technical and material support. Cemil Kavalci: analysis and interpretation of data, and critical revision of the manuscript for important intellectual content.

\section{References}

1. Eddleston M. Patterns and problems of deliberate self-poisoning in the developing world. QJM. 2000;93(11):715-31.

2. Serinken M, Karcioglu O, Sengul C, Turkcuer I, Keysan MK. Hospital costs of managing deliberate self-poisoning in Turkey. Med Sci Monit. 2008;14(3):CR152-8.

3. Kapur N, House A, Creed F, Feldman E, Friedman T, Guthrie E. General hospital services for deliberate self-poisoning: an expensive road to nowhere? Postgrad Med J.1999;75(888):599-602.

4. Hawton K, Fagg J. Trends in deliberate self poisoning and self injury in Oxford, 1976-90. BMJ. 1992;304(6839):1409-11.

5. Yeo HM. The cost of treatment of deliberate self-harm. Arch Emerg Med.1993;10(1):8-14.

6. Wax PM. History. In: Goldfrank LR, Flomenbaum NE editors. Toxicologic Emergency. 6th ed. New York: McGraw-Hill; 1998. pp. 1-14.

7. Chow P, Tierney MG, Dickinson GE. Acute Intoxications: Cases presenting to an adult emergency department. Can Fam Physician. 1992;38:1379-82.

8. Hanssens Y, Deleu D, Taqi A. Etiologic and demographic characteristics of poisoning: a prospective hospital-based study in Oman. J Toxicol Clin Toxicol. 2001;39(4):371-80.

9. Mashreky SR, Rahman F, Rahman A. Suicide kills more than 10,000 people every year in Bangladesh. Arch Suicide Res. 2013;17(4):387-96.

10. Cengiz M, Baysal Z, Ganidagli S, Altindag A. Characteristics of poisoning cases in adult intensive care unit in Sanliurfa, Turkey. Saudi Med J. 2006;27(4):497-502.

11. Greydanus DE, Calles J, Jr.. Suicide in children and adolescents. Prim Care. 2007;34(2):259-73.

12. Deveci A, Taskin EO, Erbay Dundar P, Demet MM, Kaya E, Ozmen E, et al. [The prevalence of suicide ideation and suicide attempts in Manisa City Centre]. Turk Psikiyatri Derg. 2005;16(3):170-8.

13. Devrimci-Ozguven H, Sayil I. Suicide attempts in Turkey: results of the WHO-EURO Multicentre Study on Suicidal Behaviour. Can J Psychiatry. 2003;48(5):324-9.

14. Akkose S, Bulut M, Armagan E, Cebicci H, Fedakar R. Acute poisoning in adults in the years 1996-2001 treated in the Uludag University Hospital, Marmara Region, Turkey. Clin Toxicol (Phila). 2005;43(2):105-9.

15. Tufekci IB, Curgunlu A, Sirin F. Characteristics of acute adult poisoning cases admitted to a university hospital in Istanbul. Hum Exp Toxicol. 2004;23(7):347-51.

16. Kavalci C, Demir A, Arslan ED, Yilmaz F, Durdu T, Yel C, et al. Adult Poisoning Cases in Ankara: Capital City of Turkey. Int J Clin Med. 2012;3(7):736-9.

17. Avsarogullari L, Senol V, Akdur O, Akin A, Durukan P, Ozkan S. Characteristics of acute adult poisonings in a university hospital emergency department in central Turkey: a three-year analysis. $J$ Pak Med Assoc. 2012;62(2):129-33.

18. Baydin A, Yardan T, Aygun D, Doganay Z, Nargis C, Incealtin O. Retrospective evaluation of emergency service patients with poisoning: a 3-year study. Adv Ther. 2005;22(6):650-8.

19. Boshehri B, Salimi S, Ranjbar S. Mortality from acute poisoning in urmia: a three- year retrospective study. Iran Red Crescent Med J. 2012;14(12):838-9.

20. Seghatoleslam T, Mirghaed OR, Sajadfar F, Sadr S, Zahiroddine A. A study on psycho-social factors related to children's suicide. Iran Red Crescent Med J. 2010;12(6):660-3.

21. Bjornaas MA, Hovda KE, Mikalsen H, Andrew E, Rudberg N, Ekeberg $\mathrm{O}$, et al. Clinical vs. laboratory identification of drugs of abuse in patients admitted for acute poisoning. Clin Toxicol (Phila). 2006;44(2):127-34.

22. Hawton K, Fagg J, Simkin S, Mills J. The epidemiology of attempted suicide in the Oxford area, England (1989-1992). Crisis. 1994;15(3):123-35.

23. Islambulchilar M, Islambulchilar Z, Kargar-Maher MH. Acute adult poisoning cases admitted to a university hospital in Tabriz, Iran. Hum Exp Toxicol. 2009;28(4):185-90.

24. Xu Y, Phillips MR, Wang L, Chen Q, Li C, Wu X. Retrospective identification of episodes of deliberate self-harm from emergency room registers in general hospitals: an example from Shanghai. Arch Suicide Res. 2013;17(4):345-59.

25. Lund C, Teige B, Drottning P, Stiksrud B, Rui TO, Lyngra M, et al. A one-year observational study of all hospitalized and fatal acute poisonings in Oslo: epidemiology, intention and follow-up. BMC Public Health. 2012;12:858.

26. White AM, MacInnes E, Hingson RW, Pan IJ. Hospitalizations for suicide-related drug poisonings and co-occurring alcohol overdoses in adolescents (ages 12-17) and young adults (ages 18-24) in the United States, 1999-2008: results from the Nationwide Inpatient Sample. Suicide Life Threat Behav. 2013;43(2):198-212.

27. Khurram M, Mahmood N. Deliberate self-poisoning: experience at a medical unit. J Pak Med Assoc. 2008;58(8):455-7.

28. Ozkose Z, Ayoglu F. Etiological and demographical characteristics of acute adult poisoning in Ankara, Turkey. Hum Exp Toxicol. 1999;18(10):614-8.

29. D'Mello DA, Finkbeiner DS, Kocher KN. The cost of antidepressant overdose. Gen Hosp Psychiatry. 1995;17(6):454-5.

30. Adams RH. An accident and emergency department's view of self-poisoning: a retrospective study from the United Norwich Hospitals 1978-1982. Hum Toxicol.1986;5(1):5-10.

31. Shahid M, Khan MM, Naqvi H, Razzak J. Cost of treatment of deliberate self-harm. A study from Pakistan. Crisis. 2008;29(4):213-5. 